\title{
MEMBANGUN SISTEM KOMPUTERISASI BERBASIS JAVA UNTUK PENJUALAN KACAMATA OPTIK SHINE
}

\author{
Asep Irwanto \\ Program Studi Teknik Informatika, Fakultas Teknik dan Ilmu Komputer, \\ Universitas Indraprasta PGRI \\ Jalan Raya Tengah No 80, Kelurahan Gedong, Pasar Rebo, Jakarta Timur \\ irwanto.asep@gmail.com
}

\begin{abstract}
Abstrak
Optik Shine merupakan sebuah perusahaan penjualan kacamata beserta aksesoris pendukungnya dan memerlukan sistem penjualan yang baik. Akan tetapai Optik Shine mengalami beberapa permasalahan seperti proses penjualan, stok, dan laporan masih dikerjakan secara manual, penyimpanan data masih menggunakan media sederhana. Maka dari itu peneliti ingin membangun suatu sistem informasi yang dapat membantu proses pekerjaan tersebut menjadi lebih mudah dan efisien. Sistem yang telah terkomputerisasi akan sangat membantu dalam pengolahan data-data penjualan maupun stok barang yang selanjutnya diolah menjadi laporan, serta dapat meminimalisir kehilangan atau kerusakan data-data tersebut.Tujuan perancangan sistem informasi ini agar dapat membangun sebuah aplikasi penjualan yang bisa mempermudah Optik Shine dalam menjalankan kegiatan usahanya, serta sebagai media informasi yang lebih komunikatif dan inovatif. Metodologi penelitian yang digunakan adalah metode grounded research. Peneliti mengumpulkan data-data dari Optik Shine dan mengunakannya untuk merumuskan masalah, menganalisis serta menjelaskan masalah yang ditemukan. Dari hasil penelitian yang dilakukan di Optik Shine, Peneliti menyimpulkan bahwa dengan sistem yang telah terkomputerisasi pengolahan data menjadi lebih cepat, serta kesalahan-kesalahan dalam pengolahan data juga semakin berkurang.
\end{abstract}

Kata Kunci :Sistem Informasi,Aplikasi Penjualan, Kacamata,Optik

\begin{abstract}
Optik Shine is a company that sells glasses and their supporting accessories and requires a good sales system. However, Optik Shine experienced several problems such as the sales process, stock, and reports were still done manually, data storage was still using simple media. Therefore, researchers want to build an information system that can help the work process become easier and more efficient. A computerized system will be very helpful in processing sales data and stock of goods which are then processed into reports, and can minimize loss or damage to these data. The purpose of designing this information system is to be able to build a sales application that can facilitate Optical Shine in carry out its business activities, as well as a more communicative and innovative medium of information. The research methodology used is grounded research method. Researchers collect data from Optical Shine and use it to formulate problems, analyze and explain the problems found. From the results of research conducted at Optical Shine, the researcher concludes that with a computerized system, data processing becomes faster, and errors in data processing are also decreasing.
\end{abstract}

Keywords: InformationSystem, Sales Application, Eyewear, Optical

\section{PENDAHULUAN}

Teknologi informasi saat ini sudah berkembang begitu cepatnya, salah satunya sudah menyasar ke sektor usaha penjualan. Dalam menjalankan kegiatan penjualan, perusahan butuh menyajikan informasi barang dengan cepat dan akurat untuk memberikan pelayanan terbaik kepada konsumen, memiliki pusat kontrol yang ketat terhadap data-data penjualannya, serta ketepatan dalam pembuatan laporan maupun pengambilan keputusan, hal ini dapat dilakukan dengan memanfaatkan fungsi dari sistem yang telah terkomputerisasi. Menurut (Indrajani, 2011) sistem adalah sekelompok elemen yang saling berhubungan hingga membentuk satu persatuan. Menurut (Mulyani, 2016) informasi adalah data yang sudah diolah yang ditujukan untuk seseorang, organisasi, ataupun siapa saja yang membutuhkan. Menurut (Sutarman, 2012) sistem informasi adalah sistem yang dapat didefinisikan dengan mengumpulkan, memproses, menyimpan, 
menganalisis, menyebarkan informasi untuk tujuan tertentu. Dengan begitu sistem informasi akan cocok digunakan dalam bidang usaha penjualan. Seiring meningkatnya transaksi penjualan, Optik Shine mengalami beberapa permasalahan pada sistem manual yang saat ini masih berjalan, mulai dari lambatnya proses transaksi penjualan, pemeriksaan stok barang, pembuatan laporan, hilang atau rusaknya media penyimpanan, untuk itu dibutuhkan sebuah sistem yang telah terkomputerisasi untuk memfasilitasi permasalahan tersebut. Tujuan dari penelitian ini adalah merancang dan membangun aplikasi penjualan yang dapat mempermudah dalam kegiatan transaksional dan operasional perusahaan.

\section{PENELITIAN RELEVAN}

Dalam melakukan penelitian ini, peneliti menggunakan beberapa referensi dari penelitian lain sebagai acuan untuk menghasilkan penelitian yang baik, diantaranya yaitu:

Jurnal yang buat oleh (Wongso, 2017) dengan judul "Perancangan Sistem Informasi Penjualan Berbasis Java Studi Kasus Pada Toko Karya Gemilang Pekanbaru". Hasil penelitian tersebut adalah mempermudah pekerjaan dan menghasilkan informasi-informasi yang dibutuhkan secara cepat dan akurat, sehingga sesuai sebagai acuan peneliti.

Jurnal oleh (Ananda \& Zuraidah, 2019) dengan judul "Perancangan Sistem Informasi Penjualan Barang Pada PT Asia Truk Pratama Jakarta". Hasil penelitian tersebut yaitu memproses seluruh data penjualan dengan mudah, aman, cepat dan akurat hingga menjadi sebuah laporan, dengan begitu penelitian tersebut dapat dijadikan acuan oleh peneliti.

\section{METODE PENELITIAN}

Metode penelitian yang peneliti gunakan adalah metode grounded research, yaitu suatu metode penelitian yang mendasarkan pada fakta dan menggunakan analisis perbandingan bertujuan untuk mengadakan generalisasi empiris, menetapkan konsep-konsep, membuktikan teori dan mengembangkan teori dimana pengumpulan data dan analisa data berjalan pada waktu yang bersamaan. Menurut (Yusuf, 2017) dengan menggunakan metode grounded research, peneliti akan dapat menjawab pertanyaan; bagaimanakah orang membangun teori secara induktif tentang suatu fenomena yang tampak dan data yang didapat dari lapangan dalam setting sehari-hari? Dengan kata lain, kerangka dasar yang ada jangan menggiring dan mematok peneliti.

\section{Metode Pengumpulan Data}

Metode pengumpulan data dilakukan oleh peneliti untuk memperoleh data dan informasi yang diperlukan dalam mencapai tujuan penelitian. Berikut metode pengumpulan data yang peneliti gunakan:

\section{Wawancara}

Peneliti melakukan wawancara atau mengajukan pertanyaan kepada pemilik dan karyawan Optik Shine tentang sistem penjualan yang saat ini berjalan, agar mendapatkan data dan informasi yang dibutuhkan.

2. Observasi

Peneliti melakukan pengamatan secara langsung kegiatan transaksi penjualan kacamata di Optik Shine untuk mempelajari prosesnya dan melengkapi data yang diperlukan.

3. Studi Pustaka

Peneliti membaca buku-buku yang berhubungan dengan penelitian sebagai referensi, serta mencari jurnal atau artiker ilmiah yang sesuai dari internet.

\section{HASIL DAN PEMBAHASAN}

Unified Modeling Language (UML) merupakan sebuah bahasa visual yang menjadi standar untuk menspesifikasikan, menggambarkan, membangun, dan dokumentasi dari sistem perangkat lunak (Ir. Yuni Sugiarti, 2013). Sehingga pemodelan ini cocok digunakan untuk merancang dan membangun penelitian peneliti. Menurut (Asropudin, 2013) Java adalah bahasa pemrograman untuk menciptakan isi yang aktif dalam halaman web, juga dapat dijalankan dalam semua komputer. Sehingga cocok digunakan peneliti untuk membuat aplikasi penelitian. Menurut (Antonius Nugraha Widhi Pratama, 2010) MySQL yaitu suatu sistem managemen basis data relasional yang mampu bekerja dengan cepat, kokoh dan mudah digunakan. Dengan sifat MySQL 
tersebut, peneliti merasa sesuai untuk menggunakannya sebagai pemyimpanan database aplikasi. Berikut ini adalah hasil analisis, perancangan dan keluaran dari penelitian Perancangan Aplikasi Penjualan Kacamata Pada Optik Shine:

\section{Use Case Diagram}

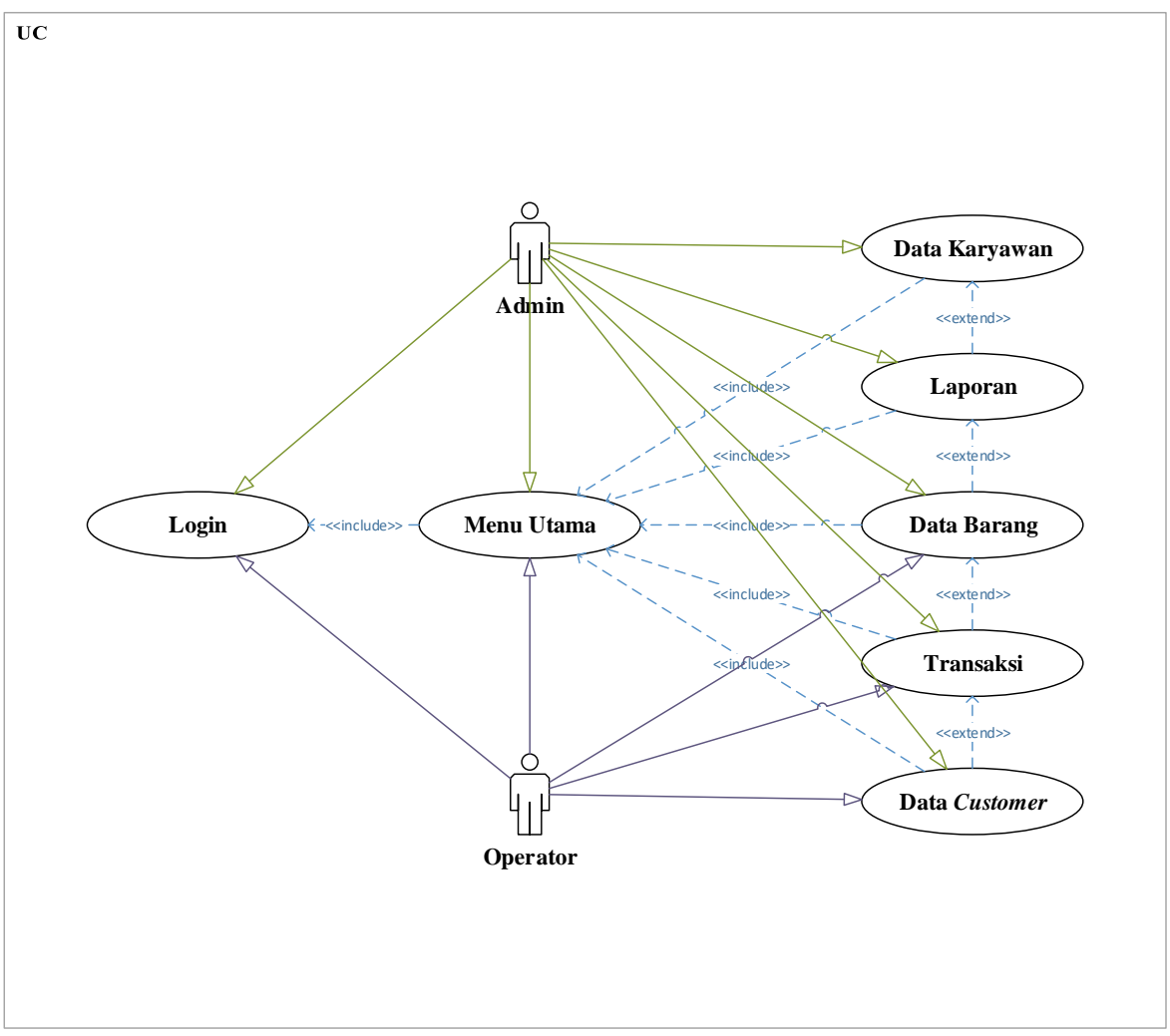

Gambar 1. Use Case Diagram

Use Case Diagram menggambarkan fungsionalitas yang diharapkan dari sebuah sistem.

\section{Activity Diagram}

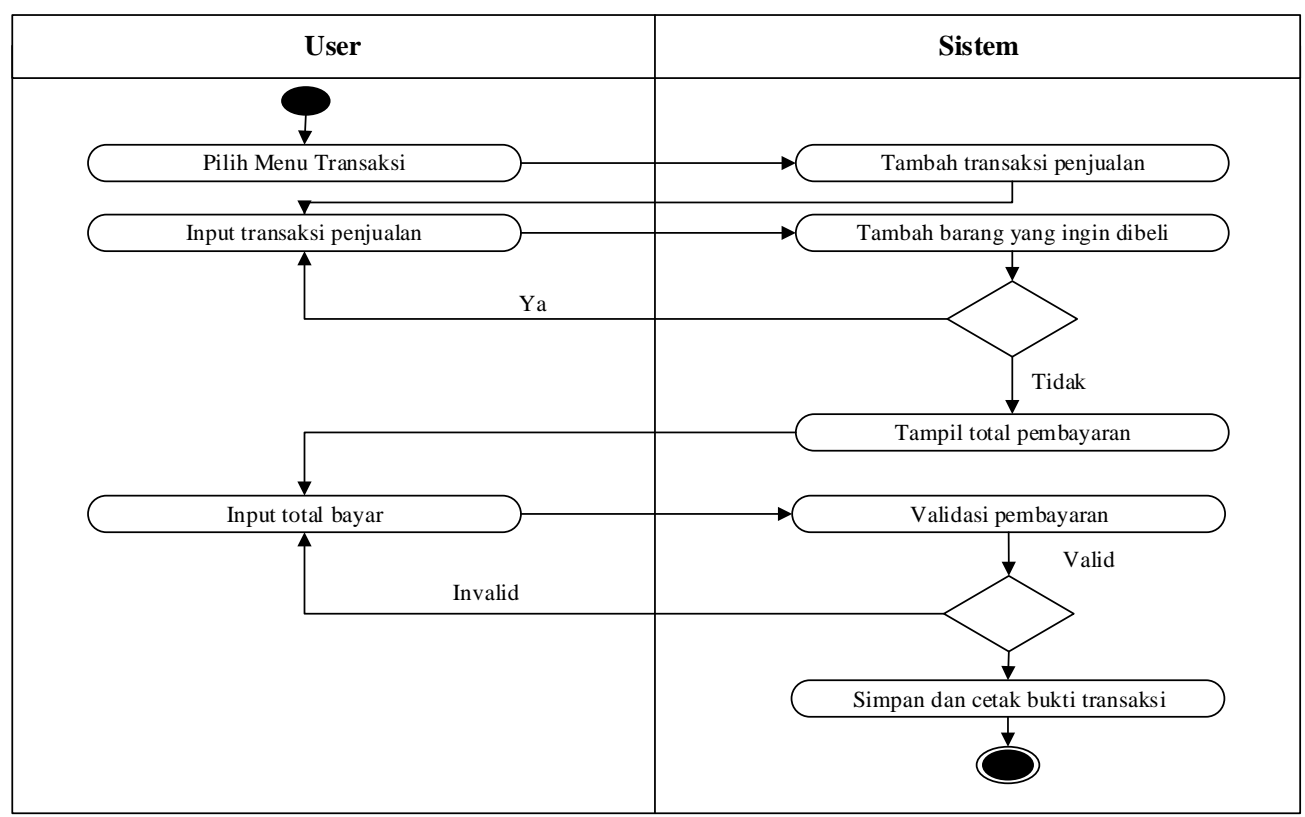

Gambar 2. Activity Diagram Transaksi

Activity Diagram menggambarkan berbagai alir aktifitas dalam sistem yang sedang dirancang. 


\section{ERD (Entity Relationship Diagram)}

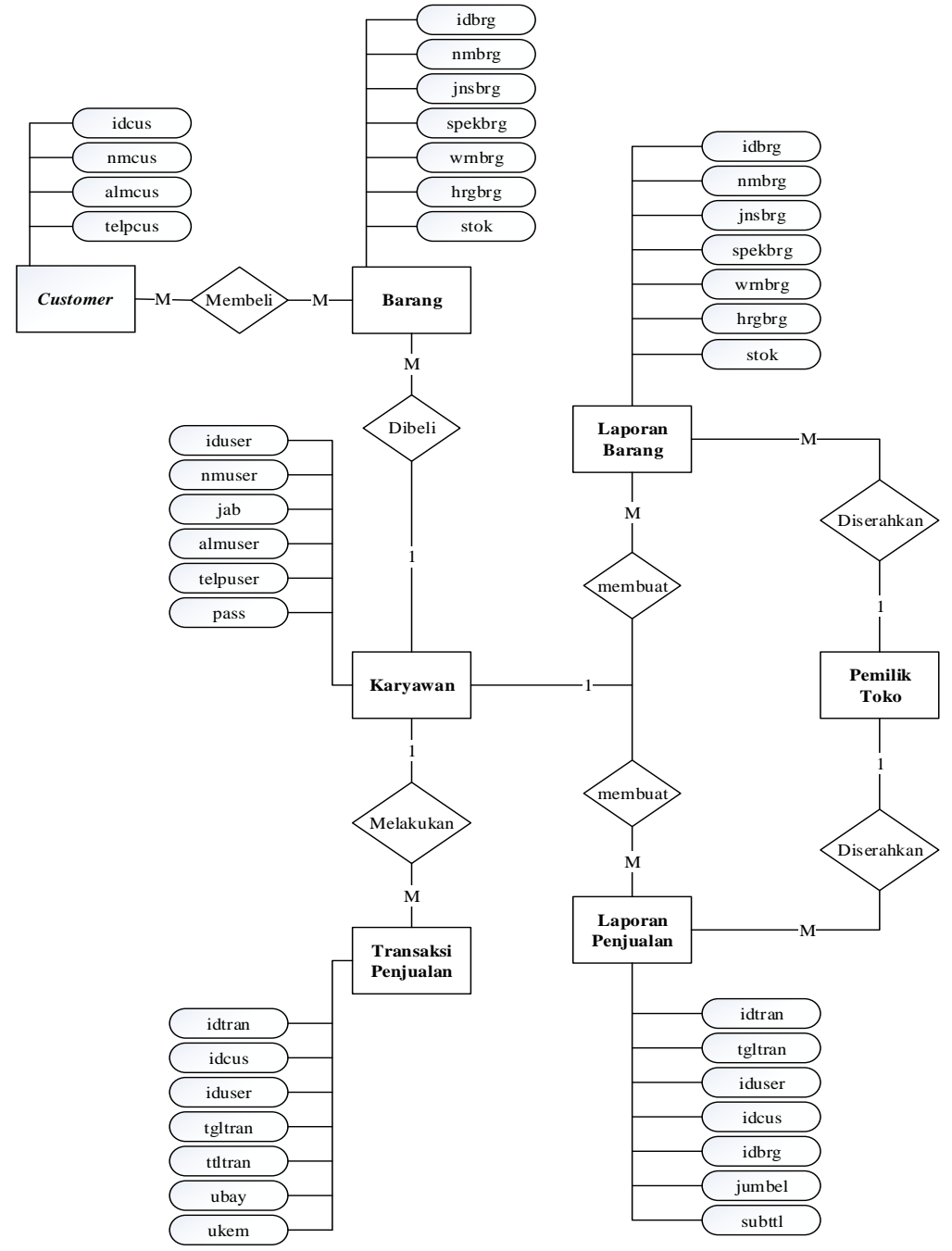

Gambar 3. Entity Relationship Diagram

Menurut (Ladjamudin, 2013) ERD (Entity Relasionship Diagram) adalah suatu model jaringan yang menggunakan data yang disimpan dari sistem secara baik atau merupakan konseptual yang mendeskripsikan hubungan-hubungan antara datastore.

Tampilan Layar Aplikasi

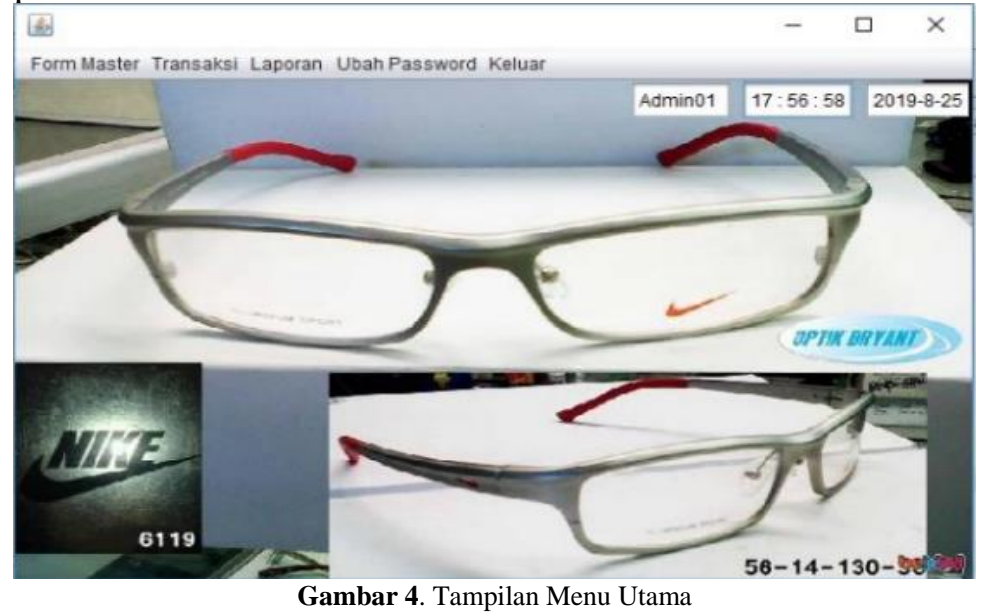


Pada tampilan menu utama terdapat menubar yang terdiri dari Form Master, Transaksi, Laporan, Ubah Password, dan Keluar.

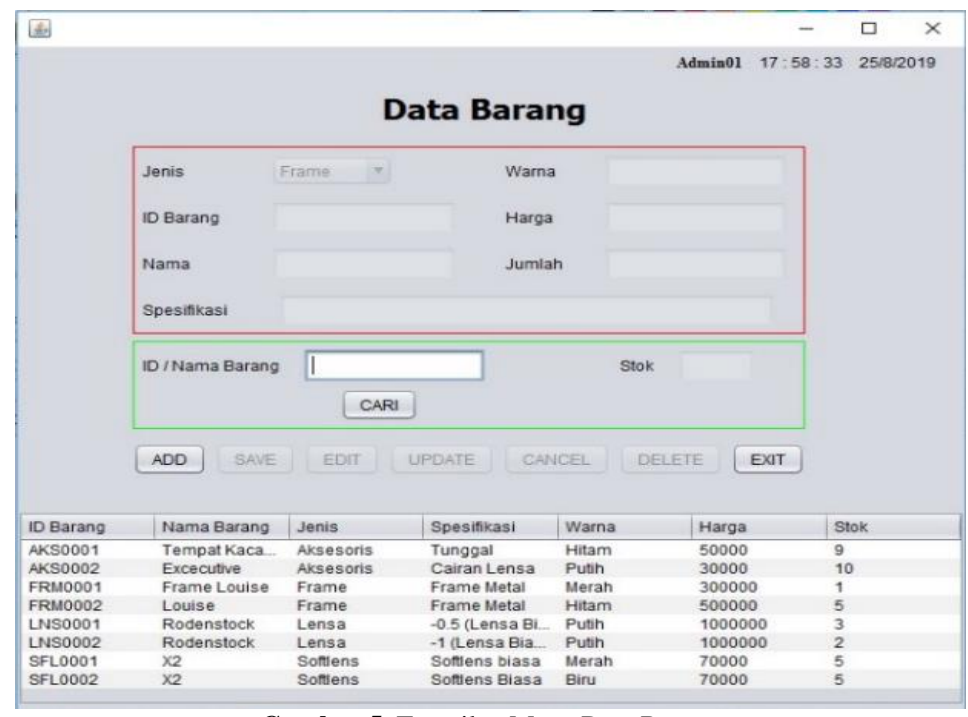

Gambar 5. Tampilan Menu Data Barang

Menu Data Barang memiliki fungsi untuk menambah, mencari, merubah, dan menghapus data barang.

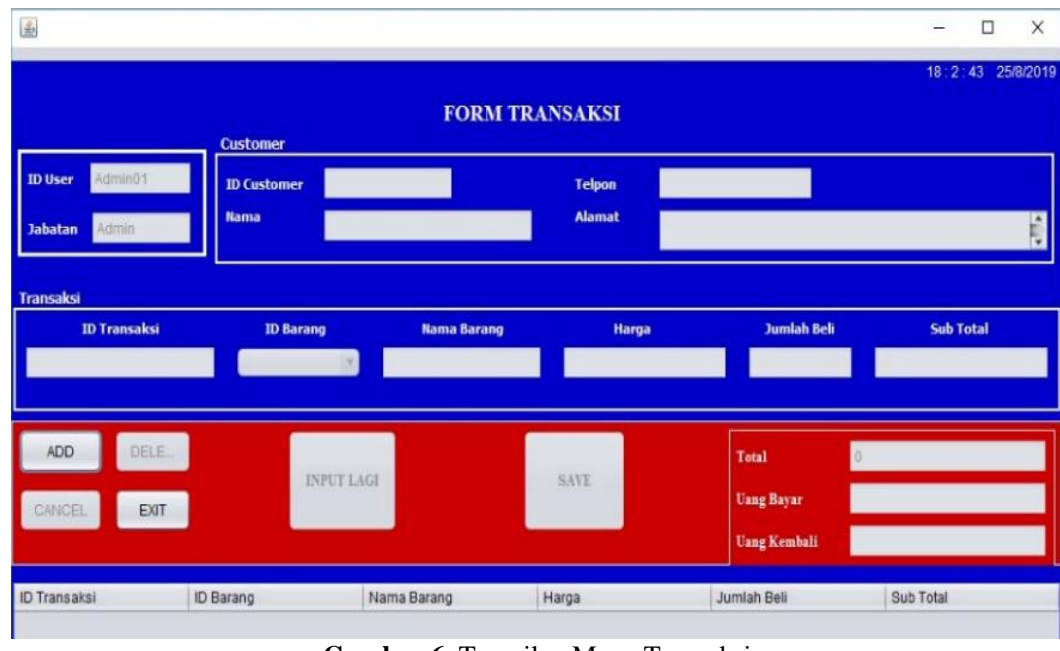

Gambar 6. Tampilan Menu Transaksi

Menu Transaksi berfungsi untuk menginput transaksi penjualan di Optik Shine dan mencetak bukti transaksinya. 


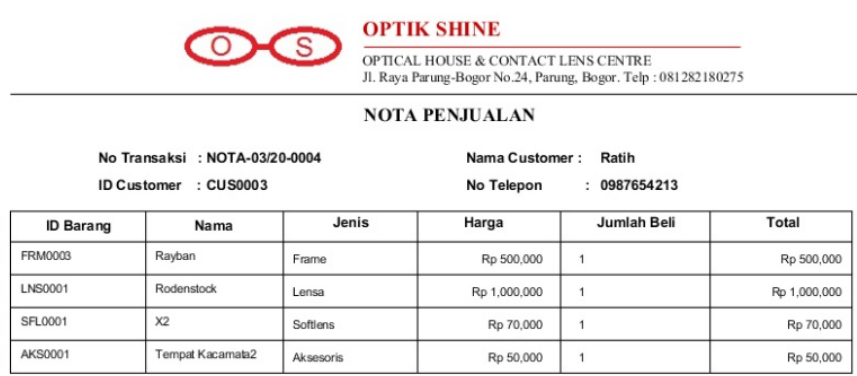
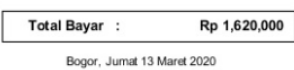

Kasir

Mohammax Ulin

Gambar 7. Tampilan Bukti Transaksi Penjualan

Tampilan diatas menginformasikan detail pembelian barang dan pembayarannya.

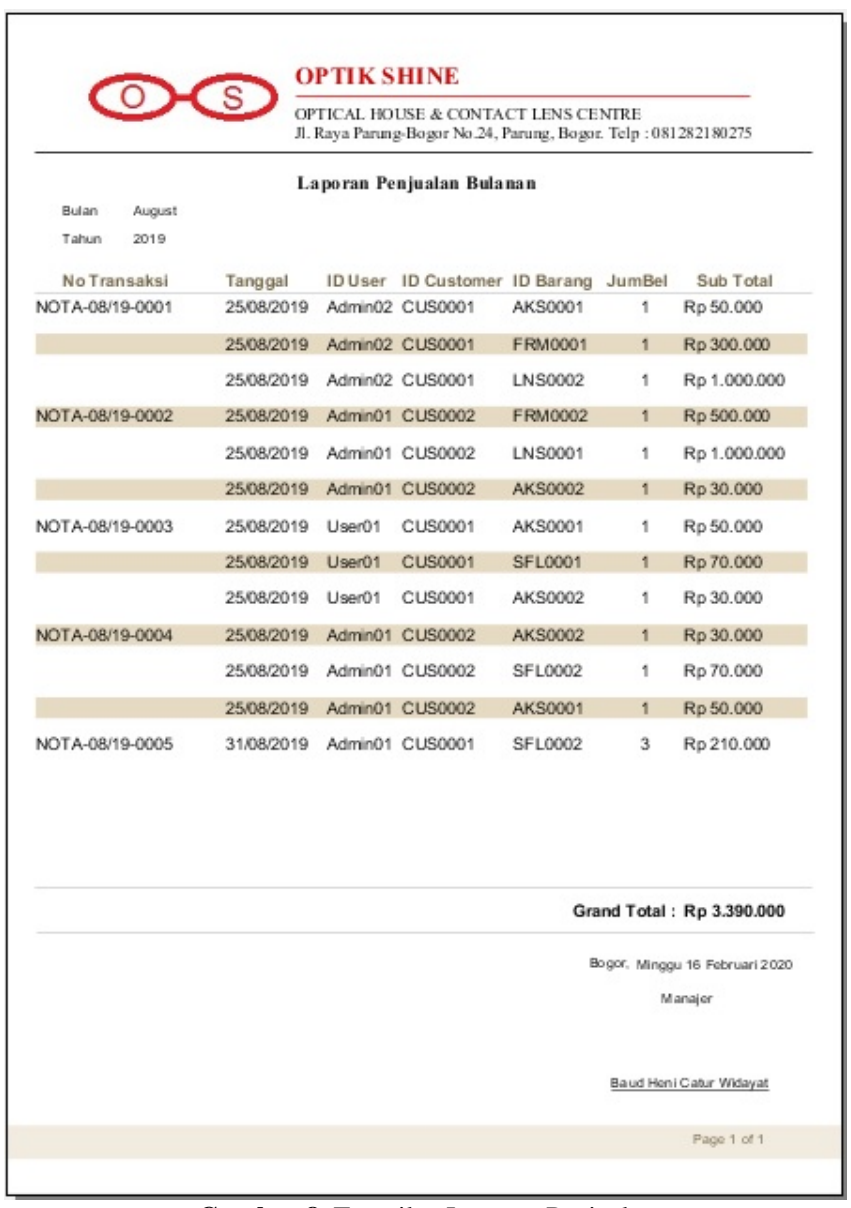

Gambar 8. Tampilan Laporan Penjualan

Tampilan diatas menginformasikan rekap transaksi penjualan selama satu bulan. 


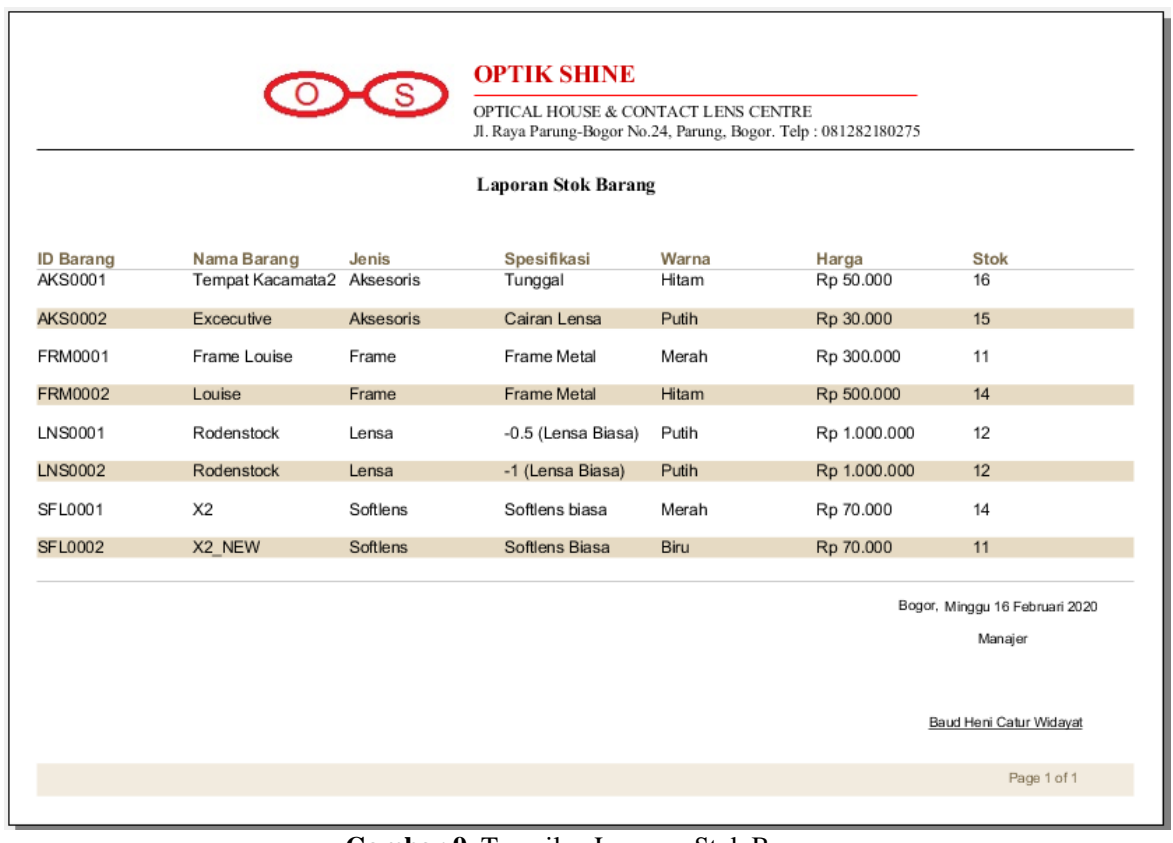

Gambar 9. Tampilan Laporan Stok Barang

Tampilan diatas menginformasikan data stok barang terbaru.

\section{SIMPULAN}

Dari hasil pembahasan penelitian diatas, dapat disimpulkan bahwa proses pengolahan data dengan menggunakan sistem komputerisasi seperti ini akan lebih membantu perusahaan dalam menjaga dan mengolah data-datanya, karena terdapat sistem keamanan didalam aplikasinya. Pelaksanaan operasioanal perusahaan menjadi lebih efektif dan efisien, karena setiap program pengolahan data saling terhubung satu sama lain. Proses pembuatan laporan penjualan dan stok barang menjadi lebih akurat, mudah, dan cepat, karena setiap elemen yang dibutuhkan didalam proses ini telah secara langsung terhubung ke dalamnya.

\section{DAFTAR PUSTAKA}

Ananda, I., \& Zuraidah, E. (2019). Perancangan Sistem Informasi Penjualan Barang Pada PT Asia Truk Pratama Jakarta. Jurnal Informatika, 6(2). https://doi.org/10.31311/ji.v6i2.6248

Antonius Nugraha Widhi Pratama. (2010). Cara Mudah Membangun Aplikasi PHP. Transmedia, Jakarta Selatan.

Asropudin, P. (2013). Kamus Teknologi Informasi Komunikasi (Kamus Bergambar). In Kamus Teknologi Informasi.

INDRAJANI. (2011). Perancangan Basis Data Dalam All in 1. In Elex Media Komputindo.

Ir. Yuni Sugiarti, M. K. (2013). Analisis \& Perancangan UML (Unified Modeling Language) Generated VB.6. In Graha Ilmu.

Ladjamudin, A.-B. Bin. (2013). Analisis dan Desain Sistem Informasi. Graha Ilmu.

Mulyani, S. (2016). Metode Analisis dan Perancangan Sistem, ISBN: 978-979-19906-2-2. Edisi Ke-2.

Sutarman. (2012). Pengantar Teknologi Informasi. Bumi Aksara.

Wongso STMIK Dharmapala Riau, F. (2017). PERANCANGAN SISTEM INFORMASI PENJUALAN BERBASIS JAVA STUDI KASUS PADA TOKO KARYA GEMILANG PEKANBARU. Jurnal Ilmiah Ekonomi Dan Bisnis, $12(1)$.

Yusuf, A. M. (2017). Metodologi Penelitian Kuantitatif, Kualitatif \& Penelitian Gabungan. In K E N C A N A (Vol. 66). K E N C A N A. https://ejournal.poltektegal.ac.id/index.php/siklus/article/view/298\%0Ahttp://repositorio. unan.edu.ni/2986/1/5624.pdf\%0Ahttp://dx.doi.org/10.1016/j.jana.2015.10.005\%0Ahttp://www.biomedcentral.com /1471-2458/12/58\%0Ahttp://ovidsp.ovid.com/ovidweb.cgi?T=JS\&P 